\title{
Antithrombotic therapy in patients with atrial fibrillation and coronary artery disease
}

\author{
Abdelmoniem Moustafa, Mohammad Ruzieh, Ehab Eltahawy, Saima Karim \\ Departments of Internal Medicine and Cardiology, University of Toledo Medical Center, Toledo, Ohio, USA
}

\begin{tabular}{|c|}
\hline Access this article online \\
\hline Website: www.avicennajmed.com \\
\hline DOI: 10.4103/ajm.ajm_73_19 \\
\hline Quick Response Code: \\
\hline
\end{tabular}

\begin{abstract}
Atrial fibrillation and coronary artery disease are commonly coexisting conditions that necessitate the use of an oral anticoagulant as well as dual antiplatelet therapy. Commonly referred to as triple oral antithrombotic therapy (TT), this helps prevent ischemic stroke and myocardial infarction but comes at the expense of an increased risk of bleeding. There is a growing body of evidence that the omission of aspirin from TT has the same preventive efficacy in terms of major adverse cardiacvascular and cerebrovascular events (MACCE) with significantly lower bleeding events. The combination of antiplatelet agents and direct oral anticoagulants (DOAC) is a matter of ongoing research. However, initial studies showed favorable safety profile of DOAC over vitamin $\mathrm{K}$ antagonist in combination with antiplatelet agents.
\end{abstract}

Key words: Atrial fibrillation, cad, dual antiplatelet therapy, triple antithrombotic therapy

\section{INTRODUCTION}

Coronary artery disease (CAD) occurs in $20 \%-30 \%$ of patients with atrial fibrillation (AF), and $5.3 \%-28 \%$ of hospitalized patients with acute coronary syndrome (ACS) develop new-onset AF during their hospitalization. ${ }^{[1-4]}$ In addition, $5 \%$ of patients undergoing percutaneous coronary artery intervention (PCI) and stent placement require longterm anticoagulation because of $\mathrm{AF}^{[5,6]}$ Patients with AF with a CHA2DS2-VASc score of two or more and ACS have indications for oral anticoagulation and dual antiplatelet therapy (DT) with aspirin and a P2Y12 receptor inhibitor. The concurrent use of all three agents, termed triple oral antithrombotic therapy (TT), significantly increases the risk of bleeding. ${ }^{[7,8]}$

Currently, oral anticoagulation is the standard of care for AF patients who have a score of two or greater in men and three or greater in women on CHA2DS2-VASc score to reduce the thromboembolic risk. According to the American Heart Association guidelines, anticoagulation options are warfarin, dabigatran, rivaroxaban, apixaban, or edoxaban. ${ }^{[9,10]}$ According to American College of Cardiology/

Address for correspondence: Dr. Abdelmoniem Moustafa, Departments of Internal Medicine and Cardiology, University of Toledo Medical Center, Toledo, Ohio, USA. E-mail: mon3melshimi@gmail.com
American Heart Association, patients with ACS should be started on aspirin and P2Y12 inhibitors whether they are a candidate for PCI or not. ${ }^{[11-13]}$ Given the aging population and increasing prevalence of risk factors for both CAD and the development of AF with age, at some point a large number of patients with AF and ACS may require triple oral antithrombotic therapy.

\section{DT VS. OAC FOR STROKE PREVENTION IN AF PATIENTS}

DT for one year is the standard of care for all patients with ACS whether the patient has undergone stent placement or is being treated medically. The Effect of Clopidogrel in addition to Aspirin in patients with acute coronary syndrome without ST-segment elevation study showed $20 \%$ reduction in the composite of cardiovascular mortality,

This is an open access journal, and articles are distributed under the terms of the Creative Commons Attribution-NonCommercial-ShareAlike 4.0 License, which allows others to remix, tweak, and build upon the work non-commercially, as long as appropriate credit is given and the new creations are licensed under the identical terms.

For reprints contact: reprints@medknow.com

Cite this article as: Moustafa A, Ruzieh M, Eltahawy E, Karim S. Antithrombotic therapy in patients with atrial fibrillation and coronary artery disease. Avicenna J Med 2019;9:123-8. 
myocardial infarction, and stroke in ACS patients who received aspirin and clopidogrel for 12 months vs. aspirin alone. In addition, subgroup analysis showed consistent results whether the patient had revascularization or not. ${ }^{[11]}$

The question arose as to whether DT was sufficient to prevent stroke in patients with concomitant AF without need for additional oral anticoagulant. Long-term efficacy of DT compared with vitamin $\mathrm{K}$ antagonist for stroke prevention was addressed in a prospective study that terminated early because of significantly higher thromboembolic events in the DT group. The results revealed an annual risk of stroke in OAC vs. DT of $3.93 \%$ vs. $5.60 \%$; with a relative risk of $1.44(1.18-1.76 ; P=0.0003) .{ }^{[14]}$ Another metaanalysis showed similar results with a minor increase in extracranial hemorrhage in the OAC group by $0.3 \% \cdot{ }^{[15]}$. Moreover, warfarin is superior to DT in reducing plasma thrombogensis marker levels in patients with $\mathrm{AF}^{[16]}$ Thus, both the United States and European guidelines do not recommend any antiplatelet therapy as a prophylaxis for stroke in patients with $\mathrm{AF}^{[9,17,18]}$

Adding an oral anticoagulant to DT comes with the risk of higher bleeding rates when compared to two antithrombotic agents. In the WOEST trial that compared warfarin plus clopidogrel vs. triple therapy, the latter group had a higher risk of bleeding ( $44.4 \%$ vs. 19.4; hazard ratio [HR], 0.36; $95 \%$ confidence interval [CI], 0.26-0.40;P<0.001). ${ }^{[7]}$ Khurram et al. found that in patients requiring anticoagulation therapy with warfarin, the addition of DT was associated with a $6.6 \%$ major bleeding risk. Rogacka et al. ${ }^{[19]}$ found a $4.7 \%$ incidence of major bleeding complications during the triple therapy. Bleeding commonly occurred within the first month of triple therapy in the majority of patients. ${ }^{[20,21]}$

\section{Duration of TT and risk of bleeding}

The absence of a major bleeding event in the first 30 days of TT does not necessarily predict outcomes up to the end of the first year of TT. Indeed, a meta-analysis that included patients with $\mathrm{AF}$ and $\mathrm{CAD}$ on TT showed that the risk of major bleeding increased by almost six-fold by the end of 12 months' therapy (12\%) compared with the first 30 day of TT (2.2\%). ${ }^{[22]}$ Moreover, the RE-LY study that compared efficacy and safety of dabigatran compared with warfarin in patients with AF showed that intracranial hemorrhage in anticoagulated patients correlates with concurrent antiplatelet therapy which was found to be the most important modifiable independent risk factor for intracranial hemorrhage $(\mathrm{HR}, 2.9, P<0.001) .{ }^{[23]}$

If shorter courses of TT decrease the risk of major bleeding, would the shorter duration of TT compromise efficacy?
The ISAR-TRIPLE trial was an open-label study that addressed the efficacy of TT based on the duration of TT. All patients in the trial received aspirin and OAC and were then randomized to six weeks of clopidogrel therapy vs. six months of clopidogrel. The primary end point was major adverse cardiovascular and cerebrovascular events (MACCE) at nine months. The results did not show a significant difference in the primary endpoint; a longer TT duration was not superior to shorter TT in terms of preventing thromboembolic events. ${ }^{[2]}$

VKA and antiplatelet therapy: How to mitigate the risk of bleeding?

Konishi et al.${ }^{[25]}$ found that in patients with AF who had PCI on TT with a therapeutic INR between 1.6 and 2.6 and a median time in the therapeutic range of $78.4 \%$, TT therapy was not associated with MACCE $(P=0.89)$ nor major bleeding $(P=0.80)$ as compared with DT. The conclusion was that a slightly lower and a tightly controlled INR may be the answer for safer TT without compromising efficacy.

The WOEST trial is a landmark study that addressed safety of $\mathrm{TT}$ as a primary end point (bleeding events) and efficacy in preventing thrombotic events as a secondary point in terms of cardiac ischemic events, stroke, and stent thrombosis. Patients with AF and CAD were randomized before coronary angiography to TT (warfarin, aspirin, clopidogrel) or DT (warfarin and clopidogrel). TT associated with a significantly higher number of bleeding events. Ironically, the results showed better efficacy with DT. The composite of secondary endpoints (death, MI, stent thrombosis, strokes) was significantly lower in DT $(11.3 \%$ vs. $17.7 \% P=0.025$ HR, 0.60, $(0.38-0.94){ }^{[7]}$

\section{DOAC as an alternative to VKA?}

This raises the question if DOACs will be a safer alternative to warfarin in TT by avoiding variation in levels of anticoagulation. Rivaroxaban was the first DOAC that had positive outcome as an add-on to DT in patients with $\mathrm{AF}$ and CAD after PCI. PIONEER AF-PCI trial examined the safety and efficacy of rivaroxaban $15 \mathrm{mg}$ daily in addition to P2Y12 (group 1), vs. rivaroxaban $2.5 \mathrm{mg}$ daily as a part TT (group 2 ), and vs. VKA plus DT (group 3) for 1, 6, or 12 months. Clinically significant bleeding was lower in the two groups receiving rivaroxaban than in the group receiving standard therapy ( $16.8 \%$ in group $1,18.0 \%$ in group 2 , and $26.7 \%$ in group 3; HR for group 1 vs. group 3, 0.59; $95 \%$ CI, $0.47-$ 0.76 ; $P<0.001$; HR for group 2 vs. group 3, 0.63; 95\% CI, $0.50-0.80 ; P<0.001)$. In addition, there was no significant difference in thrombotic events (MACCE) among the three groups. ${ }^{[26]}$ However, rivaroxaban doses used in PIONEER AF_PCI trial are lower than stroke preventive dose used in 
ROCKET AF trial. ${ }^{[27]}$ Therefore, the results of PIONEER trial should be taken with caution. Longer follow-up period and bigger study population are needed to ascertain the safety of such an approach.

In the same patient population, similar results were found when dabigatran and P2Y12 (clopidogrel or ticagrelor) based DT was compared with TT (warfarin, Aspirin and P2Y12 inhibitor). RE-DUAL PCI trial has shown superiority of dabigatran-based DT compared with TT at $110 \mathrm{mg}$ dose (included elderly $>80$ year old) in terms of bleeding events ( $15.4 \%$ vs. $26.9 \%$ (HR, 0.52 ; $95 \%$ CI, $0.42-0.63$; $P<0.001$ for noninferiority; $P<0.001$ for superiority). With non-inferiority for dabigatran $150 \mathrm{mg}$ dose $20.2 \%$ for DT vs. $25.7 \%$ for TT (HR, 0.72; 95\% CI, 0.58-0.88; $P<0.001$ for noninferiority). No significant difference in thromboembolic events was found between the two groups. Nevertheless, higher number of stent thrombosis in dabigatran 110-mg arm was found but it did not reach statistical significance. ${ }^{[28]}$

Apixaban is no exception. In AUGUSTUS trial, 4614 patients with AF and CAD were randomized to apixaban $5 \mathrm{mg}$ twice daily or vitamin $\mathrm{K}$ antagonist in addition to P2Y12 in open-label part of the study. Then the patients were randomized to aspirin or placebo. Unsurprisingly, patients received apixaban and $\mathrm{P} 2 \mathrm{Y} 12$ without aspirin had the lowest bleeding events without significant difference in mortality and ischemic events among the groups. In general, apixaban group has one-third reduction in bleeding events as compared with vitamin $\mathrm{K}$ antagonist-based antithrombotic regimen $10.5 \%$ vs. $14.7 \%$ (HR, 0.69 ; $95 \%$ CI, $0.58-0.81$; $P<0.001$ for both noninferiority and superiority). ${ }^{[29]}$

Furthermore, two recent meta-analysis addressed safety and efficacy of DT (an oral anticoagulant plus P2Y12 inhibitor) vs. conventional TT (warfarin, aspirin, and P2Y12) have shown reduction in minor and major bleeding events by half in DT compared with TT without significant difference in all-cause mortality, major adverse cardiac events, thromboembolic events, myocardial infarction, and stent thrombosis. ${ }^{[30,31]}$

DOACs in combination with DT in patient with CAD without AF

The use of DOACs in combination with aspirin and clopidogrel was studied in patients with ACS without AF [Table 1]. In the Re-DEEM study, adding different doses of dabigatran to DT vs. placebo was associated with significant increases in the risk of bleeding by $77 \%$ with the lowest dose, and up to four-fold risk with the higher doses of dabigatran without any additional benefit; for $50 \mathrm{mg}$ (HR, 1.77; 95\%
CI, 0.70-4.50); for $75 \mathrm{mg}$ (HR, 2.17; 95\% CI, 0.88-5.31); for $110 \mathrm{mg}$ (HR, 3.92; 95\% CI, 1.72-8.95); and for $150 \mathrm{mg}$ (HR, 4.27; 95\% CI, 1.86-9.81). ${ }^{[32]}$ Apixaban plus DT vs. placebo plus DT also had disappointing results and led to the early termination of the APPRAISE trial because of unacceptable rates of total bleeding. ${ }^{[33]}$

\section{Ticagrelor and prasugrel as a part of TT}

Data are scarce when it comes to other P2Y12 inhibitors as a part of TT. A Swedish study compared the safety and efficacy of TT (aspirin, clopidogrel, and warfarin) vs. DT (ticagrelor and warfarin) in patients with $\mathrm{AF}$ and CAD after stenting for only three months retrospectively. The results did not show significant differences between the two groups in terms of bleeding and thrombo-embolic events. ${ }^{[34]}$ In Re-Dual PCI trial, subgroup analysis showed a $15 \%-50 \%$ increase in bleeding event rate in patients who had taken ticagrelor as part of TT with VKA or DT with dabigatran vs. other P12Y2 inhibitors. ${ }^{[28]}$ Similar results were observed in AUGUSTUS trial where higher bleeding rate was found in patients who had received prasugrel and ticagrelor vs. clopidogrel. ${ }^{[29]}$ The results of the ongoing prospective MANJUSRI trial are eagerly anticipated--which would provide data on the better combination therapy (ticagrelor and warfarin vs. aspirin, clopidogrel, and warfarin) for patients with AF and CAD. ${ }^{[35]}$

\section{Guidelines}

According to the American Heart Association guidelines for AF that were published in 2014 and an update in 2019, it may be reasonable to use clopidogrel in combination with oral anticoagulants (without specifying a particular anticoagulant) without aspirin after coronary revascularization. ${ }^{[9,17]}$ On the contrary, the ESC 2016 guidelines adopted a shorter period of TT of a month followed by dual therapy (OAC plus a single antiplatelet). ${ }^{[18]}$

\section{CONCLUSION}

In patients with $\mathrm{AF}$ undergoing $\mathrm{PCI}$, it may be reasonable to use rivaroxaban, dabigatran, or apixaban in combination with clopidogrel without aspirin. Such combination does mitigate the risk of bleeding without compromising efficacy in terms of ischemic events and mortality. Rivaroxaban, dabigatran, and apixaban are safer as part of triple/dual therapy when compared with VKA without compromising efficacy. There is a growing body of evidence that combination of an oral anticoagulant (rivaroxaban, dabigatran, and apixaban or VKA) and P2Y12 platelet inhibitors without aspirin is as effective as TT and it carries less risk of bleeding, which would the approach of choice for high bleeding risk patients who have AF undergoing PCI. In addition, use of clopidogrel instead of ticagrelor or prasugrel as a part of DT or TT in 


\begin{tabular}{|c|c|c|c|c|c|c|c|}
\hline Study & Design & Outcome & Follow up & Population & Comparison & Bleeding endpoint & Ischemic endpoint \\
\hline $\begin{array}{l}\text { Mega et al, } 2009 \\
(32)\end{array}$ & $\begin{array}{l}\text { Randomised, double } \\
\text { blind, phase II }\end{array}$ & $\begin{array}{l}\text { Saftey endpoint:TIMI } \\
\text { bleeding (major or } \\
\text { minor) or requiring } \\
\text { medical attention), } \\
\text { efficany end point: } \\
\text { Death, MI, stroke }\end{array}$ & 6 months & $\begin{array}{l}\text { 349I patients } \\
\text { after ACS }\end{array}$ & $\begin{array}{l}\text { ASA only or } \\
\text { ASA plus } \\
\text { thienopyridine, } \\
\text { randomized to } \\
\text { receive placebo } \\
\text { or Rivaroxiban }\end{array}$ & $\begin{array}{l}\text { significant bleeding with rivaroxaban versus placebo } \\
\text { increased in a dose-dependent manner (hazard } \\
\text { ratios [HRs] } 2.21 \text { [ } 95 \% \mathrm{Cl} \text { I.25-3.9I] for } 5 \mathrm{mg}, 3.35 \\
\text { [2.3I- } \\
4.87] \text { for } 10 \mathrm{mg}, 3.60 \text { [2.32-5.58] for } 15 \mathrm{mg} \text {, and } 5.06 \\
\text { [3.45-7.42] for } 20 \mathrm{mg} \text { doses; } \mathrm{p}<0.000 \mathrm{I}\end{array}$ & $\begin{array}{l}\text { primary efficacy endpoint } \\
\text { were } 5.6 \%(126 / 2331) \text { for } \\
\text { rivaroxaban versus } 7.0 \% \\
(79 / 1160) \text { for placebo }(H R \\
0.79[0.60-1.05], p=0.10)\end{array}$ \\
\hline
\end{tabular}

\begin{tabular}{|c|c|c|c|c|c|}
\hline $\begin{array}{l}\text { APPRAISE } \\
\text { Steering } \\
\text { Committee and } \\
\text { investigators et al, } \\
2009\end{array}$ & $\begin{array}{l}\text { Double blinded, } \\
\text { placebo controlled, } \\
\text { phase II }\end{array}$ & $\begin{array}{l}\text { Primary outcome: } \\
\text { Major or non- } \\
\text { Major bleeding, } \\
\text { seconday outcome: } \\
\text { cardiovascular death, } \\
\text { myocardial infarction, } \\
\text { severe recurrent } \\
\text { ischemia, or ischemic } \\
\text { stroke }\end{array}$ & 6 months & $\begin{array}{l}\text { I7I5 patients } \\
\text { with STEMI } \\
\text { and STEMI and } \\
\text { I additional } \\
\text { risk factor for } \\
\text { ischemic event }\end{array}$ & $\begin{array}{l}5-20 \mathrm{mg} \\
\text { Nearly all } \\
\text { received ASA } \\
\text { and } 76 \% \text { received } \\
\text { Plavix, patient } \\
\text { randmoized to } \\
\text { different doses } \\
\text { of Apixaban or } \\
\text { placebo }\end{array}$ \\
\hline
\end{tabular}

$10 \mathrm{mg}$ BID and $20 \mathrm{mg}$ daily were terminated early Apixiban resulted in lower due to excess total bleed. Compared with placebo, rates of secondary end $\begin{array}{ll}\text { apixaban } 2.5 \mathrm{mg} \text { twice daily (hazard ratio, I.78; } & \text { point. However, ithe ncrease }\end{array}$ $95 \%$ confidence interval, 0.91 to $3.48 ; \mathrm{P}=0.09$ ) and $\quad$ in bleeding was more $\begin{array}{ll}\text { Committee and phase II } & \text { Major bleeding, } \\ \text { investigators et al, } & \text { seconday outcome }\end{array}$ myocardial infarction, $10 \mathrm{mg}$ once daily (hazard ratio, $2.45 ; 95 \%$ confidence pronounced and the reduction ischemia, or ischemic

$\begin{array}{llll}\text { oldgren et al, } & \begin{array}{l}\text { Randomized, } \\ \text { double- }\end{array} & \begin{array}{l}\text { Primary outcome } \\ \text { was major or minor }\end{array} & \begin{array}{l}\text { Up to } 28 \\ \text { weeks }\end{array}\end{array}$

blind, phase II trial bleeding, secondary outcome was reduction in D-Dimer levels or CVD ischemic events

Dewilde et al, Open-Label, Primary safety

2013 randomizes,

endpoint: Bleed within controlled trial I year, secondary myocardial infarction, stroke, targetvessel revascularisation

Gibson et al, 2016 Randomized, controlled, open label Primary safety outcome was clinically significant bleeding, secondary end point
12 months

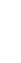

\section{unde}

Anti-coagulation Bleeding episodes were seen in 54 (19.4\%) patients

receiving anti- plus plavis (double receiving double therapy and in $126(44.4 \%)$

$186 \mathrm{I}$ patient DAPT with bleeding: Dose-dependent increase with dabigatran, Fourteen (3.8\%) patients died, with NSTEMI different strength hazard ratio (HR) 1.77 (95\% confidence intervals had a myocardial infarction and STEMI with of Dabigatran or $0.70,4.50$ ) one major risk placebo factors for CVD

1,6,
12 months

2124 patients Low dose with Non-valular rivaroxiban + atrial fibrillation thienopyridine undergoing $\mathrm{PCl}$ (groupl), Low (group I), Low $\quad P<0.001$; hazard ratio for group 2 vs. group $3,0.63$; dose rivaroxiban+ $95 \% \mathrm{Cl}, 0.50$ to $0.80 ; \mathrm{P}<0.00 \mathrm{I}$ ) + DAPT (group2), Warfarin with INR receiving 0.26 $0.50, p<0.0001)$

or stroke in the placebo group compared with 17 $(4.6 \%)$ in $50 \mathrm{mg}, 18(4.9 \%)$ in $75 \mathrm{mg}, 12(3.0 \%)$ in $110 \mathrm{mg}$, and $12(3.5 \%)$ in the $150 \mathrm{mg}$ dabigatran groups

3I $(\mathrm{I} \mid \mathrm{I} \%)$ patients in the double-therapy group and in (herapy) or plus therapy group After correction for imbalance in baseline characteristics, the HR remained similar $(0.56,95 \% \mathrm{Cl}$ 0.35-0.91).

Bleeding $(16.8 \%$ in group $\mathrm{I}, 18.0 \%$ in group 2 , and Death from cardiovascular $26.7 \%$ in group 3 ; hazard ratio for group I vs. group causes, myocardial infarction, $3,0.59 ; 95 \%$ confidence interval $[\mathrm{Cl}], 0.47$ to 0.76 ; or stroke were similar in the three groups (KaplanMeier estimates, $6.5 \%$ in group I, $5.6 \%$ in group 2 , and $6.0 \%$ in group $3 ; P$ values for all comparisons were nonsignificant).

Lopres et al, 2019 Randomized, Primary outcome: major and clinically relevant non major bleeding. Secondary outcome: composite of death and hospitalization and composite of death and ischemic events

7 months $\quad 4614$ patients Apixaban+ Bleeding events $10.5 \%$ in apixaban group vs $14.7 \%$ in with atrial $\mathrm{P} 2 \mathrm{Y} 12+/-$ fibrillation and Aspirin Vs VKA

coronary artery +P2YI2+/-

disease Aspirin

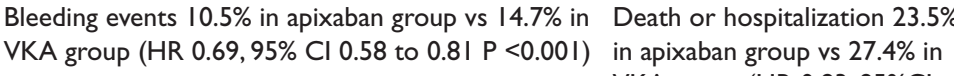
VKA group ( $\mathrm{HR} 0.83,95 \% \mathrm{Cl}$ 0.770 to $0.93, P=0.002$ ) Similar incidence of ischemic event 
patients at high risk of bleeding is associated with lower bleeding event.

\section{Financial support and sponsorship}

Nil.

\section{Conflicts of interest}

There are no conflicts of interest.

\section{REFERENCES}

1. Nieuwlaat R, Capucci A, Camm AJ, Olsson SB, Andresen D, Davies DW, et al. Atrial fibrillation management: a prospective survey in ESC member countries [Internet]. Eur Heart J 2005;26:2422-34.

2. Nabauer M, Gerth A, Limbourg T, Schneider S, Oeff M, Kirchhof P, et al. The registry of the German competence network on atrial fibrillation: patient characteristics and initial management. Europace 2009; 11:423-34.

3. Elewa H, Ahmed D, Barnes GD. Triple oral antithrombotic therapy in atrial fibrillation and coronary artery stenting: searching for the best combination. Semin Thromb Hemost 2016;42:662-70.

4. Thomsen PEB, Jons C, Pekka Raatikainen MJ, Joergensen RM, Hartikainen J, Virtanen $\mathrm{V}$, et al. Long-term recording of cardiac arrhythmias with an implantable cardiac monitor in patients with reduced ejection fraction after acute myocardial infarction [Internet]. Circulation 2010;122:1258-64.

5. Rossini R, Musumeci G, Lettieri C, Molfese M, Mihalcsik L, Mantovani P, et al. Long-term outcomes in patients undergoing coronary stenting on dual oral antiplatelet treatment requiring oral anticoagulant therapy. Am J Cardiol 2008;102:1618-23.

6. Rubboli A, Colletta M, Valencia J, Capecchi A, Franco N, Zanolla L, et al. WARfarin and Coronary STENTing (WAR-STENT) Study Group. Periprocedural management and in-hospital outcome of patients with indication for oral anticoagulation undergoing coronary artery stenting. J Interv Cardiol 2009;22:390-7.

7. Dewilde WJM, Oirbans T, Verheugt FWA, Kelder JC, De Smet BJ, Herrman J-P, et al. Use of clopidogrel with or without aspirin in patients taking oral anticoagulant therapy and undergoing percutaneous coronary intervention: an open-label, randomised, controlled trial [Internet]. Lancet 2013;381:1107-15.

8. Orford JL, Fasseas P, Melby S, Burger K, Steinhubl SR, Holmes DR, et al. Safety and efficacy of aspirin, clopidogrel, and warfarin after coronary stent placement in patients with an indication for anticoagulation. Am Heart J 2004;147:463-7.

9. Nishimura RA, Otto CM, Bonow RO, Carabello BA, Erwin JP, Guyton RA, et al. 2014 AHA/ACC guideline for the management of patients with valvular heart disease [Internet]. J Am Coll Cardiol 2014;63:e57-e185.

10. January CT, Wann LS, Calkins H, Chen LY, Cigarroa JE, Cleveland JC, et al. 2019 AHA/ACC/HRS focused update of the 2014 AHA/ACC/HRS guideline for the management of patients with atrial fibrillation: a report of the American College of Cardiology/American Heart Association Task Force on Clinical Practice Guidelines and the Heart Rhythm Society. J Am Coll Cardiol 2019; 25873. Available from: http://www.onlinejacc. org/content/accj/early/2019/01/21/j.jacc.2019.01.011.full.pdf?_ $\mathrm{ga}=2.123833999 .444342634 .1549998980-1712963828.1549998980$.

11. Massachusetts Medical Society. Effects of clopidogrel in addition to aspirin in patients with acute coronary syndromes without ST-segment elevation. N Engl J Med 2001;345:494-502.

12. for Percutaneous Cardiovascular Interventions EA, Others. The task force on myocardial revascularization of the European Society of Cardiology (ESC) and the European Association for Cardio-Thoracic Surgery (EACTS). Eur Heart J 2010;31:2501-55.
13. Amsterdam EA, Wenger NK, Brindis RG, Casey DE, Ganiats TG, Holmes DR, et al. 2014 AHA/ACC guideline for the management of patients with non-ST-elevation acute coronary syndromes: executive summary [Internet]. Circulation 2014;2354-94.

14. Waldo AL. Clopidogrel plus aspirin versus oral anticoagulation for atrial fibrillation in the atrial fibrillation clopidogrel trial with irbesartan for prevention of vascular events (ACTIVE W): a randomised controlled trial [Internet]. Yearb Cardiol 2007;423-4.

15. Hart RG, Pearce LA, Aguilar MI. Meta-analysis: antithrombotic therapy to prevent stroke in patients who have nonvalvular atrial fibrillation. Ann Intern Med 2007;146:857-67.

16. Kamath S, Blann AD, Chin BS, Lip GY. A prospective randomized trial of aspirin-clopidogrel combination therapy and dose-adjusted warfarin on indices of thrombogenesis and platelet activation in atrial fibrillation. J Am Coll Cardiol 2002;40:484-90.

17. January CT, Samuel Wann L, Calkins H, Chen LY, Cigarroa JE, Cleveland JC, et al. 2019 AHA/ACC/HRS focused update of the 2014 AHA/ACC/HRS guideline for the management of patients with atrial fibrillation [Internet].Circulation 2019;140:e 125,e 151.

18. Kirchhof P, Benussi S, Kotecha D, Ahlsson A, Atar D, Casadei B, et al. 2016 ESC guidelines for the management of atrial fibrillation developed in collaboration with EACTS. Europace 2016;18:1609-78.

19. Khurram Z, Chou E, Minutello R, Bergman G, Parikh M, Naidu S, et al. Combination therapy with aspirin, clopidogrel and warfarin following coronary stenting is associated with a significant risk of bleeding. J Invasive Cardiol 2006;18:162-4.

20. Rogacka R, Chieffo A, Michev I, Airoldi F, Latib A, Cosgrave J, et al. Dual antiplatelet therapy after percutaneous coronary intervention with stent implantation in patients taking chronic oral anticoagulation. JACC Cardiovasc Interv 2008;1:56-61.

21. Asencio LA, Huang JJ, Alpert JS. Combining antiplatelet and antithrombotic therapy (triple therapy): What are the risks and benefits? Am J Med 2014;127:579-85.

22. Faxon DP, Eikelboom JW, Berger PB, Holmes DR Jr, Bhatt DL, Moliterno DJ, et al. Antithrombotic therapy in patients with atrial fibrillation undergoing coronary stenting: a North American perspective: executive summary. Circ Cardiovasc Interv 2011;4:522-34.

23. Hart RG, Diener HC, Yang S, Connolly SJ, Wallentin L, Reilly PA, et al. Intracranial hemorrhage in atrial fibrillation patients during anticoagulation with warfarin or dabigatran: the RE-LY trial. Stroke 2012;43:1511-7.

24. Fiedler KA, Maeng M, Mehilli J, Schulz-Schüpke S, Byrne RA, Sibbing D, et al. Duration of triple therapy in patients requiring oral anticoagulation after drug-eluting stent implantation: the ISAR-TRIPLE trial. J Am Coll Cardiol 2015;65:1619-29.

25. Konishi H, Miyauchi K, Kasai T, Tsuboi S, Ogita M, Naito R, et al. Adequate time in therapeutic INR range using triple antithrombotic therapy is not associated with long-term cardiovascular events and major bleeding complications after drug-eluting stent implantation [Internet]. J Cardiol 2016;68:517-522.

26. Gibson CM, Michael Gibson C, Mehran R, Bode C, Halperin J, Verheugt FW, et al. Prevention of bleeding in patients with atrial fibrillation undergoing PCI [Internet]. N Engl J Med 2016;375:2423-34.

27. Patel MR, Mahaffey KW, Garg J, Pan G, Singer DE, Hacke W, et al. ROCKET AF Investigators. Rivaroxaban versus warfarin in nonvalvular atrial fibrillation. N Engl J Med 2011;365:883-91.

28. Cannon CP, Bhatt DL, Oldgren J, Lip GYH, Ellis SG, Kimura T, et al. REDUAL PCI Steering Committee and Investigators. Dual antithrombotic therapy with dabigatran after $\mathrm{PCl}$ in atrial fibrillation. $\mathrm{N}$ Engl J Med 2017;377:1513-24.

29. Lopes RD, Heizer G, Aronson R, Vora AN, Massaro T, Mehran R, et al. AUGUSTUS Investigators. Antithrombotic therapy after acute coronary syndrome or PCI in atrial fibrillation. N Engl J Med 2019;380:1509-24.

30. Agarwal N, Jain A, Mahmoud AN, Bishnoi R, Golwala H, Karimi A, et al. Safety and efficacy of dual versus triple antithrombotic therapy in 
patients undergoing percutaneous coronary intervention. Am J Med 2017;130:1280-9.

31. Golwala HB, Cannon CP, Steg PG, Doros G, Qamar A, Ellis SG, et al. Safety and efficacy of dual vs. Triple antithrombotic therapy in patients with atrial fibrillation following percutaneous coronary intervention: a systematic review and meta-analysis of randomized clinical trials. Eur Heart J 2018;39:1726-35a.

32. Oldgren J, Budaj A, Granger CB, Khder Y, Roberts J, Siegbahn A, et al. RE-DEEM Investigators. Dabigatran vs. placebo in patients with acute coronary syndromes on dual antiplatelet therapy: a randomized, double-blind, phase II trial. Eur Heart J 2011;32:2781-9.

33. Alexander JH, Becker RC, Bhatt DL, Cools F, Crea F, Dellborg M, et al. APPRAISE Steering Committee and Investigators. Apixaban, an oral, direct, selective factor Xa inhibitor, in combination with antiplatelet therapy after acute coronary syndrome: results of the Apixaban for Prevention of Acute Ischemic and Safety Events (APPRAISE) trial. Circulation 2009;119:2877-85.

34. Braun OÖ, Bico B, Chaudhry U, Wagner H, Koul S, Tydén P, et al. Concomitant use of warfarin and ticagrelor as an alternative to triple antithrombotic therapy after an acute coronary syndrome. Thromb Res 2015;135:26-30.

35. Lu W, Chen L, Wang Y, Yao Y, Fu C, Zuo P, et al. Rationale and design of MANJUSRI trial: A randomized, open-label, active-controlled multicenter study to evaluate the safety of combined therapy with ticagrelor and warfarin in $\mathrm{AF}$ subjects after PCl-eS [Internet]. Contemp Clin Trials 2015;40:166-71. 